\title{
Solvents Fractionation, Characterization and Evaluation of Antimicrobial Activities of Beeswax from Apismelifera
}

\author{
Adewale Fatai Adeyemi ${ }^{1 *}$, Ayotunde Olalekan Afolabi ${ }^{2}$, Zainab Ariyike Usman ${ }^{2}$ and Isaac Ayodeji Adesina ${ }^{3}$ \\ ${ }^{I}$ Department of Chemistry, University Medical Sciences, Ondo City, Nigeria \\ ${ }^{2}$ Department of Physical and Earth Sciences (Industrial Chemistry Unit), Wesley University Ondo, Nigeria \\ ${ }^{3}$ Department of Biological Sciences(Microbiology Unit), University of Medical Sciences Ondo, Nigeria \\ *Corresponding author: A. F. Adeyemi \\ DOI: https://dx.doi.org/10.51584/IJRIAS.2021.6404
}

\begin{abstract}
The variations in the compositions and properties of the unfractionated beeswax and its fractions were investigated with a view to widening the scope of applications of beeswax. Beeswax from Apismeelifera was fractionated using solvents and Methanol, n-hexane, dimethylsulphoxide and diethyl ether were employed. The chemical parameters, antibacterial and antifungi activities as well as FTIR analyses of the beeswax and its fractions were carried out. The chemical parameters of the unfractionated beeswax were within the international standards ranges but most for the fractions were outside the ranges. The nhexane and diethyl ether fractions were found to be richer in esters and hydrocarbon; while the methanol and dimethylsulphoxide fractions were richer in unsaturated free fatty acids and fatty alcohols. The methanol and dimethylsulphoxide fractions showed stronger antimicrobial activities than unfractionated wax, with the dimethylsulphoxide fraction giving the best inhibitory effects. The results showed that fractionating beeswax into its simpler constituents would add values to this underutilised material.
\end{abstract}

Keywords: Beeswax, honeycomb, fractionation, FTIR, chemical parameters, antimicrobial activity

\section{INTRODUCTION}

B eeswax (white or yellow) is a product made from the honeycombs of the bees. It is a natural wax produced in wax glands located in the abdomen of worker bees and used in the construction of combs. A honeycomb is a mass of hexagonal wax cells built by honey bees in their nests to contain their larvae, stores of honey and pollen. Generally, beeswax consists of a complex mixture of saturated and unsaturated aliphatic hydrocarbons, mono-, di- and poly esters, hydroxy esters, free fatty acids, free fatty alcohols and minor of other compounds. Crude beeswax contains a large number of minor components (e.g. terpenoids and flavonoids), most of which appear to be plant-derived ([1], [2]). Reference [2] reported that there are more than 300 individual components in beeswax from various species of honeybees and more than 100 of them are volatile. The colour of the wax depends to some extent on the type of flora visited by the bees and volatile products have also been detected at low levels ([1], [3], [4]). Oxygenated compounds produced by the bees are also present, amongst which decanal, 1-decanol, nonanal, octanal, furfural, and benzaldehyde are responsible for the bouquet of the wax [3]. Many authors reported that the chemical composition of beeswax depends on its origin, age, and climatic conditions ([5] - [8]).

In the earliest time it was exploited for various purposes such as preservation of mummies, square wax writing tablets, bending agent, and for sealing and waterproofing. Although beeswax is now partly replaced by synthetic or fossil products, it plays an important role in a number of fields such as polymer technology, symbolic and artistic fields, preparation of cosmetics or medicinal commodities, food, pharmaceutical, and pesticides ([7], [9] -[12]).

Literature survey revealed that most published research works on beeswax and its applications had been centred on the whole (unfractionated) material and that its compositions vary from one region or locality to another. Fractionation of beeswax from different regions into its simpler constituent components and characterisation of the fractions may further extend the applications of beeswax and make it value added material.

\section{MATERIALS AND METHODS}

\section{A. Materials and their Procurement}

Raw beeswaxes (honeycombs from which honey has been extracted) samples from Apismelifera were collected from beekeepers in Ondo City, Nigeria. The chemicals used were obtained from certified manufacturers and suppliers through registered chemical suppliers in Nigeria. These include: n-hexane (GFS Chemicals), Diethyl ether (INDENTA Chemicals), Dimethylsulphoxide (KERMEL), Silica gel of 60-120mesh and Sodium hydroxide (OXFORD), Potassium hydrogen phthalate (AR China), Iodine chloride, Starch indicator, Acetone, Hydrochloric acid, Methanol, Ethanol, and Chloroform (British Drug House (BDH)), Muller Hinton Agar and Potato Dextrose Agar (Biotec), Nutrient Agar (Oxoid), Potassium Hydroxide (LOBA Chemie), Sodium Thiosulphate (Kermel). 


\section{B. Purification of Beeswax}

The honeycombs were packed in a clean cotton cloth (felt) and dipped in hot water regulated at $65-70^{\circ} \mathrm{C}$ on a thermostatic hot plate. The beeswax melted out through the felt onto the hot water leaving the impurities behind. The floated hot beeswax was allowed to cool to room temperature and the solid was then removed from the water. The process was repeated until very pure beeswax was obtained.

\section{Solvents Fractionation of Beeswax Samples}

Beeswax sample of $24.0 \mathrm{~g}$ was dissolved in $400 \mathrm{~mL}$ of $n$-hexane. The resulting solution was mixed with $50 \mathrm{~mL}$ methanol in a separating funnel, shook vigorously for 15 minutes, allowed to partition and then collected separately into flasks. The n-hexane fraction was further extracted for four more times with $50 \mathrm{~mL}$ methanol per batch. Each of the fractions was then concentrated using a rotary evaporator RE 52A. In a similar manner, same mass of beeswax was fractionated using diethyl ether as solvent and dimethylsuphoxide as extractant.

\section{Determination of Chemical Parameters}

The chemical parameters were determined for both the whole and the fractionated samples. For the Saponification value (SV), accurately measured $25.0 \mathrm{~mL}$ of $0.5 \mathrm{M}$ alcoholic $\mathrm{KOH}$ was added to $3.0 \mathrm{~g}$ of each sample and the mixture was refluxed for 120 minutes at $70^{\circ} \mathrm{C}$. The solution was cooled to room temperature and titrated against $0.5 \mathrm{M} \mathrm{HCl}$ to phenolphthalein end point. Bank determination was also carried out. The saponification value was calculated using the following equation:

$$
S V=\frac{(B-S) \times M \times 56.1}{\text { Weight of sample }}
$$

$B$ and $S$ are the respective volume of titrant $(\mathrm{mL})$ for the blank and sample titrations. $\mathrm{M}$ is the molarity of $\mathrm{HCl}$ and 56.1 is molecular weight of $\mathrm{KOH}$.

For the Free Fatty Acid Value (FFAV), $0.25 \mathrm{~g}$ sample was dissolved in $20 \mathrm{~mL}$ chloroform and titrated against $0.5 \mathrm{M} \mathrm{KOH}$ to phenolphthalein indicator end point. The free fatty acid was calculated as follows:

$$
F F A V=\frac{\text { titre value }(\mathrm{mL}) \times M \times 56.1}{\text { Weight of sample }} 2
$$

$M$ is the molarity of KOH solution. The difference between the saponification value and the free fatty acid value gave the ester value.

For the iodine value (IV), $20 \mathrm{~mL}$ chloroform was added to $0.3 \mathrm{~g}$ of each sample followed by addition of $25 \mathrm{~mL}$ of $25 \% \mathrm{ICl}$ solution. The mixture was left in a dark place for an hour and after that $25 \mathrm{~mL}$ of $25 \% \mathrm{KOH}$ solution was added. The resulting solution was titrated against $0.1 \mathrm{M}$ $\mathrm{Na}_{2} \mathrm{~S}_{2} \mathrm{O}_{3}$ solution till the colour changed to a pale yellow after which 2-3 $\mathrm{mL}$ of starch solution was added (as indicator) and the titration was continued till the blue colour just disappeared. Bank determination was also carried out. The iodine value was calculated by using the following equation:

$$
I V=\frac{(B-S) \times M \times 126.9 \times 10^{3}}{\text { Weight of sample }}
$$

$B$ and $S$ have same definitions in given equation $1 . M$ is the molarity of $\mathrm{Na}_{2} \mathrm{~S}_{2} \mathrm{O}_{3}$ and 126.9 is the molecular weight of iodine.

For the peroxide value (PV), Chloroform of $20 \mathrm{~mL}$ and glacial acetic acid of $15 \mathrm{~mL}$ were added to $0.25 \mathrm{~g}$ of beeswax sample. Accurately measured $5 \mathrm{~mL}$ of $10 \% \mathrm{KI}$ was added to the mixture and the resulting solution was left in dark cupboard for one hour. Titration against $0.1 \mathrm{M} \mathrm{Na}_{2} \mathrm{~S}_{2} \mathrm{O}_{3}$ solution was carried out till the colour changed to pale yellow and then $2 \mathrm{~mL}$ of starch indicator was added and the titration was continued till the disappearance of the blue colour. A similar procedure was repeated for the blank solution. The peroxide value was calculated using the following equation:

$$
P V=\frac{(S-B) \times M \times 1000}{\text { Weight of sample }}
$$

$B$ and $S$ have same definitions in given equation 1 . $\mathrm{M}$ is the molarity of $\mathrm{Na}_{2} \mathrm{~S}_{2} \mathrm{O}_{3}$ solution.

The whole beeswax and its fractions were also analysed for compositions using SHIMADZU FT-IR-8400S.

\section{E. Antimicrobial Screening of the Beeswax and its Fractions}

The anti-microbial analysis was use to evaluate the bioactivity the whole beeswax and its fractions samples. The bacteria used were clinical isolates, obtained from General Hospital Akure, Nigeria and ObafemiAwolowo University Teaching Hospital, Ile-Ife, Nigeria; while the fungi used (Beauveriabassiana, Cordycepsmilitaisand Candida albicans) were gotten from Brazil (soil) Pelotas, Rio Grande do Sul and South Africa, Mooreesburg, Western Cape Province. All the bacterial cultures were checked for purity and maintained on Mueller Hinton agar slant for bacteria and Potato dextrose agar for fungi.

Antimicrobial activity studies of the whole beeswax and its fractions (dimethylsulphoxide, Methanol, n-Hexane and diethyl ether fractions) were carried out using Agar diffusion techniques [13]. The inoculum was prepared by inoculating the test organism in mullerhinton broth and incubated for 24 hours at $37^{\circ} \mathrm{C}$ for bacteria; while for fungi, potato dextrose broth was used and incubated for 48 hours at $25^{\circ} \mathrm{C}$. After incubation, the mirco-organisms were well grown.

Muller Hinton agar was used as the growth medium and was prepared according to manufacturer's instruction, sterilized at $121^{\circ} \mathrm{C}$ for 15 minutes. A volume of $20 \mathrm{~mL}$ of the sterile medium was poured into a sterilized petri dishes allowed to cool and solidify. The sterile medium was seeded 
with $0.1 \mathrm{~mL}$ of the standard inoculum of the test microorganisms; the inoculum was spread evenly over the surface of the medium with a sterile swab-stick. The seeded plates were allowed to dry in an incubator at $37^{\circ} \mathrm{C}$ for 30 minutes. A standard cork-borer of $8 \mathrm{~mm}$ in diameter was use to cut cups (well) at the centre of each inoculated medium and $0.1 \mathrm{~mL}$ of both extracts solution was introduced separately into each well on the medium, the plates were incubated at $37^{\circ} \mathrm{C}$ for 24 hours for bacteria and $25^{\circ} \mathrm{C}$ for 48 hours for fungi after which the plates were observed for zones of inhibitions of growth. The zones were measured and the result recorded to the nearest millimetres. Filter paper disc containing solvent of extraction served as a negative control, the antimicrobial activities were tested in duplicate and the mean zone of inhibitions was calculated for each.

\section{RESULTS AND DISCUSSION}

\section{A. Characterisation}

Table 1 presents the fractional percentages of beeswax in the solvents, while Table 2 displays the mean values of the chemical parameters of the beeswax samples and their fractions. Only about $10 \%$ were in the dimethylsulphoxide layer in the diethyl etherdimethylsulphoxide fractionation, while about $20 \%$ were in the methanol layer in the n-hexane-methanol fractionation.
The chemical parameters for the unfractionated beeswax were within the international standard ranges. The acid value (17.882 $\mathrm{mg} \mathrm{KOH} / \mathrm{g}$ ) is at the lower end of the standard range; thus very low level of rancidity could result on storage. The beeswax samples and their fractions contained no peroxide value. This showed that both the whole and the fractions are stable to oxidation processes, during storage and transportation.

The dimethylsulphoxide fraction has the highest iodine and acid values. It is followed by methanol fraction; while n-hexane and diethyl ether fractions were high in ester and saponification values. These results show that most of the unsaturated and free fatty acid components of the wax were in these polar solvents layers, leaving most of the esters and saturated hydrocarbons in non-polar n-hexane and diethyl ethers layers. None of the fractions had ester to acid ratio within the international standard range for unfractionated beeswax (Table 1).

Table I. Percentage Fractional Yields

\begin{tabular}{|c|c|c|c|c|}
\hline Fraction & $\mathrm{M}_{\mathrm{F}}$ & $\mathrm{nH}_{\mathrm{F}}$ & DMSO $_{\mathrm{F}}$ & $\mathrm{DEE}_{\mathrm{F}}$ \\
\hline Yield (\%) & 19.86 & 80.14 & 10.22 & 89.78 \\
\hline
\end{tabular}

$\mathrm{M}_{\mathrm{F}}=$ methanol fraction; $\mathrm{nH}_{\mathrm{F}}=\mathrm{n}$-hexane fraction; $\mathrm{DEE}_{\mathrm{F}}=$ diethyl ether fraction; $\mathrm{DMSO}_{\mathrm{F}}=$ dimethylsulphoxide fraction

Table II. The Mean Chemical Parameters of the Beeswax Samples and their Fractions

\begin{tabular}{|c|c|c|c|c|c|c|}
\hline Parameter & $\mathrm{BW}_{\mathrm{U}}$ & $\mathrm{M}_{\mathrm{F}}$ & $\mathrm{nH}_{\mathrm{F}}$ & $\mathrm{DEE}_{\mathrm{F}}$ & $\mathrm{DMSO}_{\mathrm{F}}$ & International Standard* $\left(\mathrm{BW}_{\mathrm{U}}\right)$ \\
\hline PV (meq/kg sample) & 0.000 & 0.000 & 0.000 & 0.000 & 0.000 & Not specified \\
\hline IV ( $\mathrm{g} \mathrm{I}_{2} / 100 \mathrm{~g}$ sample) & 8.621 & 10.018 & 7.598 & 7.942 & 10.694 & Not specified \\
\hline AV (mg KOH/g sample) & 17.882 & 25.015 & 11.301 & 9.800 & 31.680 & $17-24$ \\
\hline $\mathrm{SV}$ (mg KOH/g sample) & 92.525 & 66.881 & 89.569 & 88.144 & 58.088 & $83-103$ \\
\hline EV (mg KOH/g sample) & 75.315 & 41.866 & 78.268 & 78.344 & 26.408 & $66-82$ \\
\hline EAR & 4.212 & 1.674 & 6.926 & 7.994 & 0.834 & $3.00-4.30$ \\
\hline
\end{tabular}

$\mathrm{BW}_{\mathrm{U}}=$ unfractionated beeswax; $\mathrm{M}_{\mathrm{F}}=$ methanol fraction; $\mathrm{nH}_{\mathrm{F}}=\mathrm{n}$-hexane fraction; $\mathrm{DEE}_{\mathrm{F}}=$ diethyl ether fraction; $\mathrm{DMSO}_{\mathrm{F}}=$ dimethylsulphoxide fraction; $\mathrm{PV}=$ peroxide value; $\mathrm{IV}=$ iodine value; $\mathrm{AV}=$ acid value; $\mathrm{SV}=$ saponification value; $\mathrm{EV}=$ ester value; $\mathrm{EAR}=$ ester to acid ratio

*Source: [6], [8], [14-[16]

Figure 1-5 show the SHIMADZU FT-IR spectra of the unfractionated beeswax and the fractions in the wavenumber range of $4000-500 \mathrm{~cm}^{-1}$. That for whole beeswax (Figure 1) has highest number of detectable peaks, which confirms its complexity. All the samples contain absorption peaks at around 2918 to $2914 \mathrm{~cm}^{-1}\left(\mathrm{CH}_{2}\right.$ asymmetric stretch), 2850 to $2848 \mathrm{~cm}^{-1}\left(\mathrm{CH}_{2}\right.$ symmetric stretch), 1464 to $1414 \mathrm{~cm}^{-1}\left(\mathrm{CH}_{2}\right.$ and $\mathrm{CH}_{3}$ bending vibration), 1377 to $1315 \mathrm{~cm}^{-1}\left(\mathrm{CH}_{3}\right.$ bending vibration), 1290 to $1026 \mathrm{~cm}^{-1}$ (C-O stretch of alcohol, ester, free fatty acid), 3300 to 3500 $\mathrm{cm}^{-1}$ (OH stretch of alcohol)and 719 to $705 \mathrm{~cm}^{-1}$ (long-chain $\left(\mathrm{CH}_{2}\right)$ band).

The spectrum for the DMSO fraction (Figure 5) is distinct while those for the unfractionated beeswax and for methanol, n-hexane and diethyl ether fractions are similar
(Figure 1-4). The DMSO fraction has strong and broad peak at around $3450 \mathrm{~cm}^{-1}$ and strong band at $1026 \mathrm{~cm}^{-1}$ representing $\mathrm{OH}$ stretch and $\mathrm{C}-\mathrm{O}$ stretch of alcohol and free fatty acid. Other characteristic features include medium but broad band at about $1645 \mathrm{~cm}^{-1}$ for $\mathrm{C}=\mathrm{O}$ stretch (fatty acid) and $\mathrm{C}=\mathrm{C}$ stretch (olefin), and a distinct peak at around $3001 \mathrm{~cm}^{-1}$ for olefinic $\mathrm{C}-\mathrm{H}$ stretch which for others fractions appears as shoulder slightly below $3000 \mathrm{~cm}^{-1}$ (possibly due to conjugation). These showed that the DMSO fraction was rich in unsaturated fatty alcohols and fatty acids. These results corroborated the high iodine value (high degree of unsaturation) and high acid value in the DMSO fraction (Table 2).

Though having similar spectra, there were variations in the relative abundance of the peaks of the spectra in Figure 
1-4 as reflected in the variations of their peak areas and corresponding areas (Table 3). Again, the whole unfractionated wax had highest peak areas and corresponding areas for most of the bands. The low ester value of the methanol fraction compared to n-hexane and diethyl ether fractions (Table 2) is also shown in their peak areas and corresponding areas $\mathrm{C}=\mathrm{O}$ stretch for ester (Table 3) where methanol fraction had the least. Furthermore, the n-hexane and diethyl ether fractions showed no detectable peak areas and corresponding areas for $\mathrm{C}=\mathrm{O}$ stretch for free fatty acid, hence their low acid values (Table 2). Also, notable distinction in abundance were observed for $1413-1416 \mathrm{~cm}^{-1}$ band $\left(\mathrm{CH}_{2}\right.$ bending -hydrocarbon) where $\mathrm{n}$-hexane and diethyl ether fractions were more in abundance; $1629-1638$ $\mathrm{cm}^{-1}$ band $(\mathrm{C}=\mathrm{C}$ stretch $)$ where methanol fraction took the lead; 2850 and $2918.4 \mathrm{~cm}^{-1}$ (symmetry and asymmetry C-H stretch) where n-hexane and diethyl ether fractions predominate; $3430-3451 \mathrm{~cm}^{-1}$ ( $\mathrm{OH}$ stretch for alcohol, free fatty acid) in which methanol fraction was the largest. These results were in agreement with those for chemical parameters (Table 2) and showed that the n-hexane and diethyl ether fractions were richer in esters and hydrocarbon; while the methanol and dimethylsulphoxide fractions were richer in unsaturated free fatty acids and fatty alcohols.

\section{[B] $=$-IMADze}

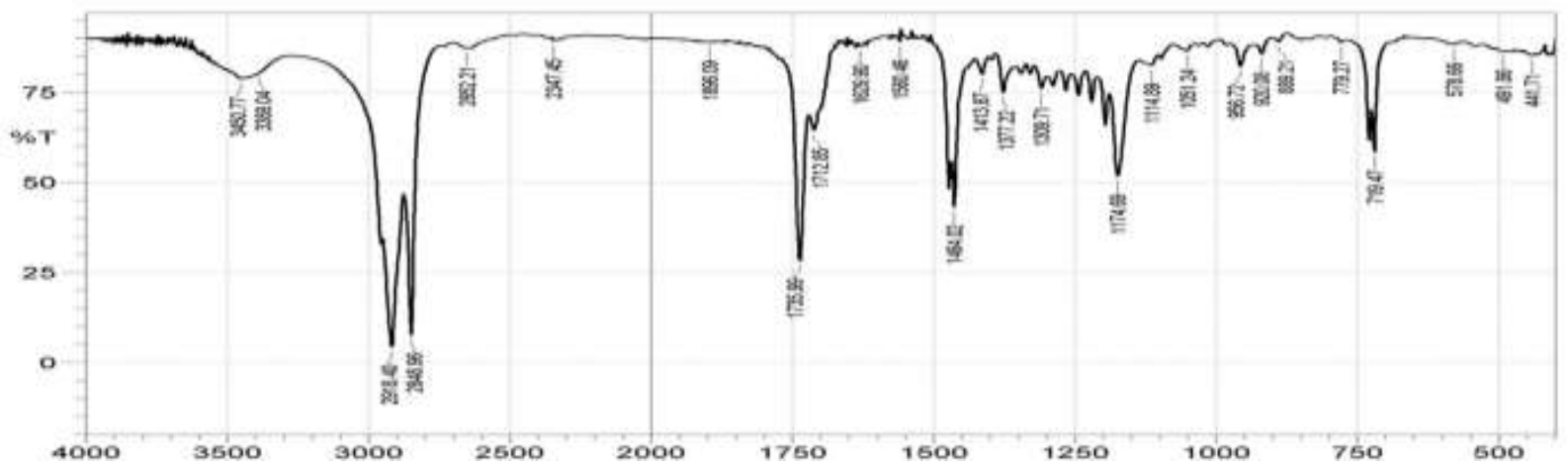

Fig 1. FTIR spectrum for the unfractionated beeswax sample

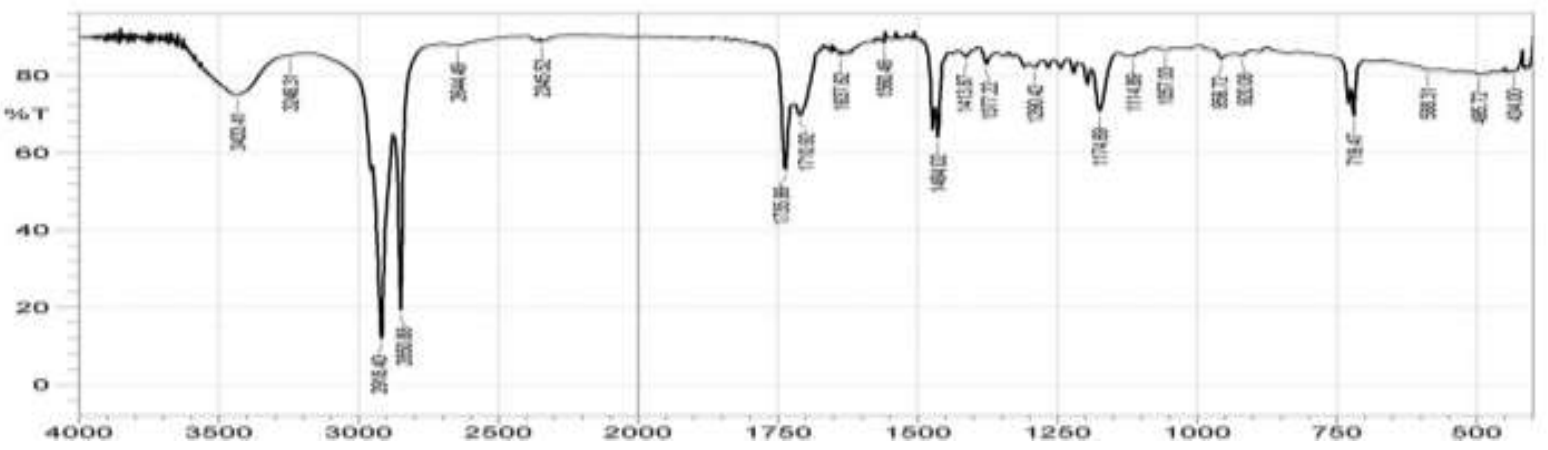

Fig 2. FTIR spectrum for the methanol fraction

[9] SHIMADZU

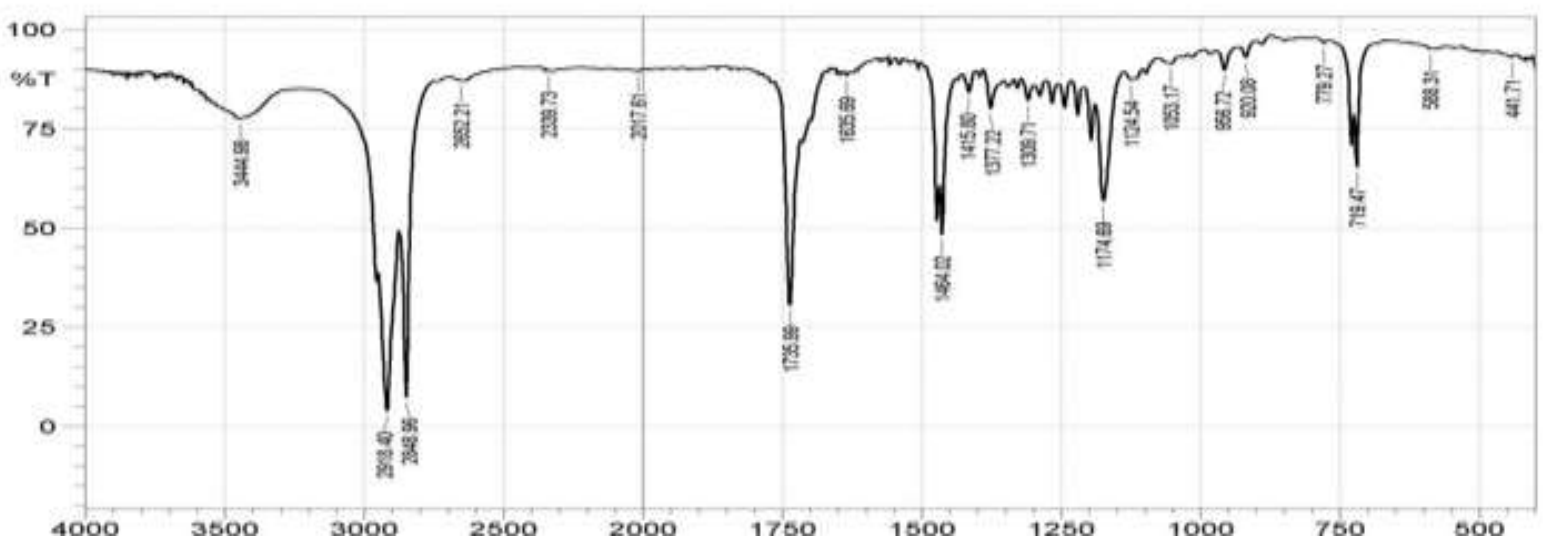

Fig 3. FTIR spectrum for the n-hexane fraction 


\section{↔IHIMADZU}

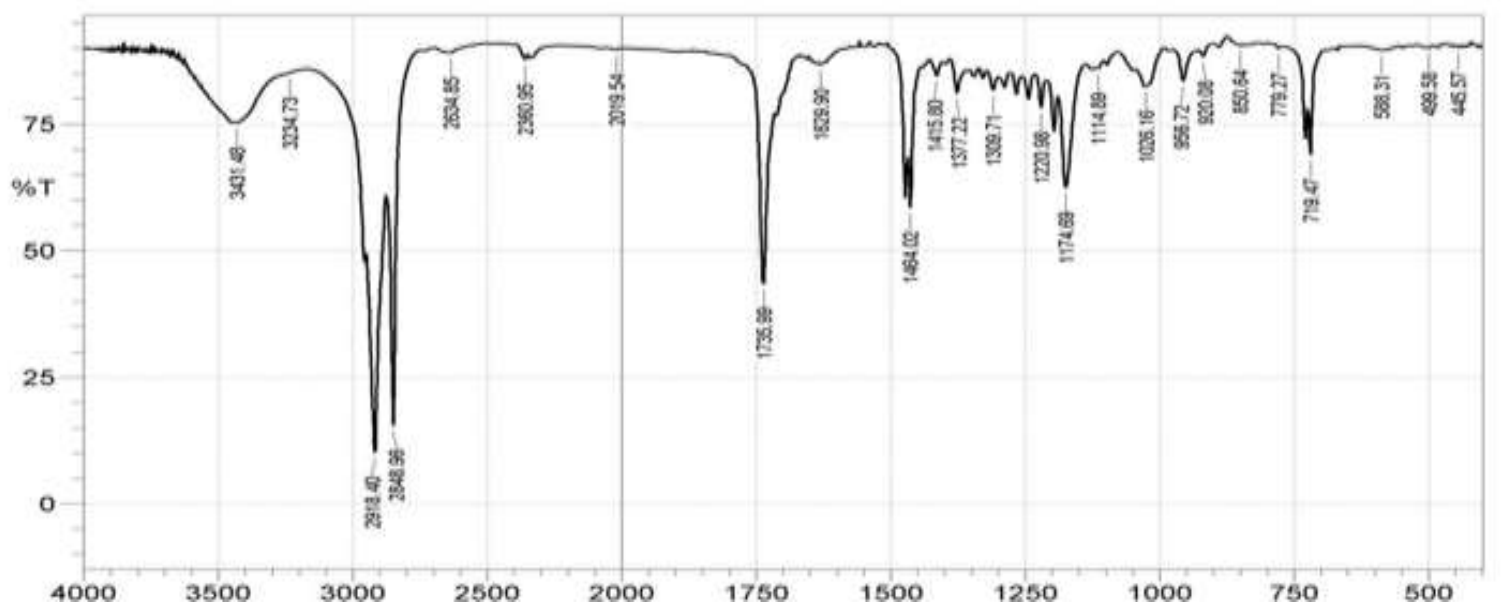

Fig 4. FTIR spectrum for the diethyl ether fraction

Ф9HIMADZU

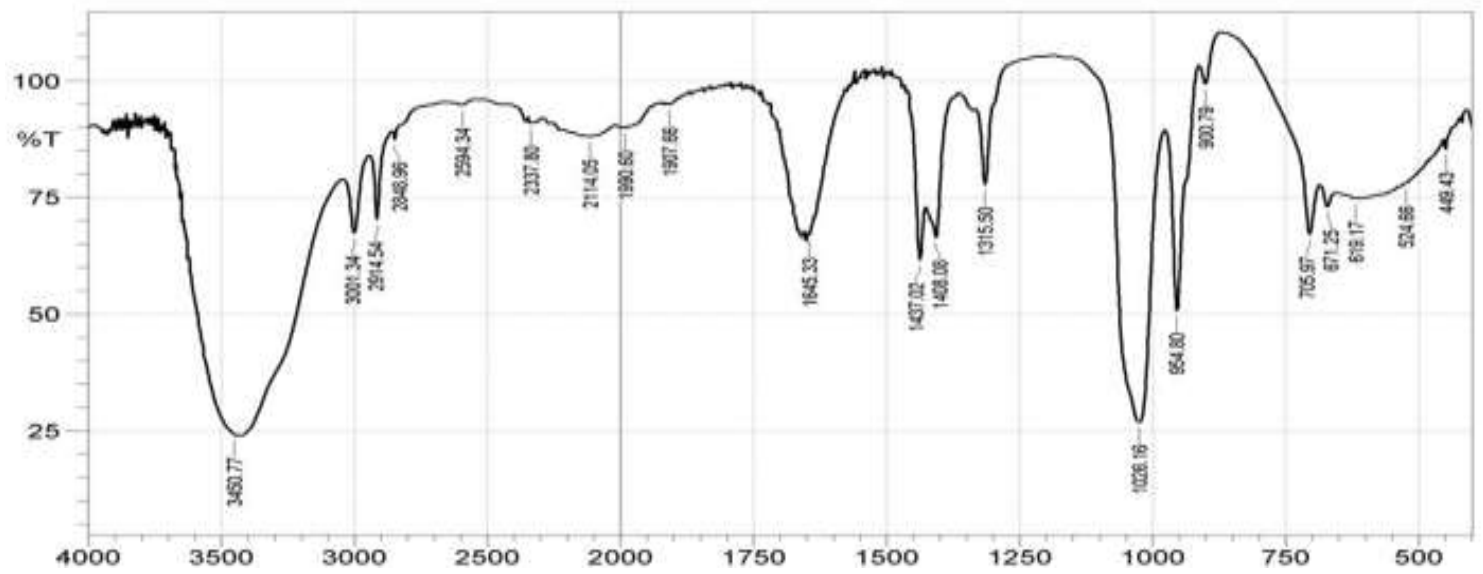

Fig 5. FTIR spectrum for the dimethylsulphoxide fraction

Table III. Variation in Area and Corresponding Area of FTIR Spectral Peaks of Unfractionated Beeswax and Methanol, n-Hexane and Diethyl ether Fractions

\begin{tabular}{|c|c|c|c|c|}
\hline Peak $\left(\mathrm{cm}^{-1}\right)$ & Sample & Area & Corr. Area & Bond vibration type \\
\hline \multirow[t]{4}{*}{$889-851$} & $\mathrm{BW}_{\mathrm{U}}$ & 1.132 & 0.070 & \multirow{12}{*}{ 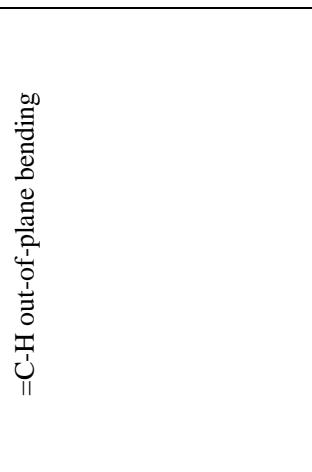 } \\
\hline & $\mathrm{M}_{\mathrm{F}}$ & - & - & \\
\hline & $\mathrm{nH}_{\mathrm{F}}$ & - & - & \\
\hline & $\mathrm{DEE}_{\mathrm{F}}$ & 1.150 & 0.010 & \\
\hline \multirow[t]{4}{*}{920.08} & $\mathrm{BW}_{\mathrm{U}}$ & 1.571 & 0.118 & \\
\hline & $\mathrm{M}_{\mathrm{F}}$ & 1.810 & 0.030 & \\
\hline & $\mathrm{nH}_{\mathrm{F}}$ & 0.570 & 0.120 & \\
\hline & $\mathrm{DEE}_{\mathrm{F}}$ & 1.260 & 0.060 & \\
\hline \multirow[t]{4}{*}{956.72} & $\mathrm{BW}_{\mathrm{U}}$ & 2.481 & 0.387 & \\
\hline & $\mathrm{M}_{\mathrm{F}}$ & 2.360 & 0.100 & \\
\hline & $\mathrm{nH}_{\mathrm{F}}$ & 1.130 & 0.290 & \\
\hline & $\mathrm{DEE}_{\mathrm{F}}$ & 2.630 & 0.460 & \\
\hline \multirow[t]{4}{*}{$1026-1057$} & $\mathrm{BW}_{\mathrm{U}}$ & 2.243 & 0.159 & \multirow{6}{*}{ 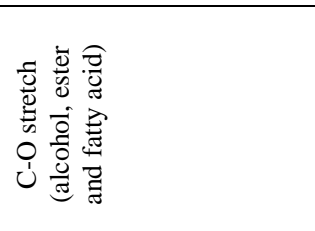 } \\
\hline & $\mathrm{M}_{\mathrm{F}}$ & 1.900 & 0.050 & \\
\hline & $\mathrm{nH}_{\mathrm{F}}$ & 0.630 & 0.030 & \\
\hline & $\mathrm{DEE}_{\mathrm{F}}$ & 3.660 & 0.660 & \\
\hline \multirow[t]{2}{*}{$1124.54-1114.89$} & $\mathrm{BW}_{\mathrm{U}}$ & 8.170 & 3.099 & \\
\hline & $\mathrm{M}_{\mathrm{F}}$ & 5.090 & 1.200 & \\
\hline
\end{tabular}




\begin{tabular}{|c|c|c|c|c|}
\hline & $\mathrm{nH}_{\mathrm{F}}$ & 6.470 & 3.000 & \\
\hline & $\mathrm{DEE}_{\mathrm{F}}$ & 5.980 & 2.080 & \\
\hline \multirow[t]{4}{*}{1174.69} & $\mathrm{BW}_{\mathrm{U}}$ & 8.170 & 3.099 & \\
\hline & $\mathrm{M}_{\mathrm{F}}$ & 5.090 & 1.200 & \\
\hline & $\mathrm{nH}_{\mathrm{F}}$ & 6.470 & 3.000 & \\
\hline & $\mathrm{DEE}_{\mathrm{F}}$ & 5.980 & 2.080 & \\
\hline \multirow[t]{4}{*}{$1290-1310$} & $\mathrm{BW}_{\mathrm{U}}$ & 2.356 & 0.221 & \multirow{4}{*}{ 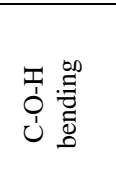 } \\
\hline & $\mathrm{M}_{\mathrm{F}}$ & 2.200 & 0.080 & \\
\hline & $\mathrm{nH}_{\mathrm{F}}$ & 1.760 & 0.210 & \\
\hline & $\mathrm{DEE}_{\mathrm{F}}$ & $1.800 ; 1.780$ & $0.230 ; 0.150$ & \\
\hline \multirow[t]{4}{*}{1377.22} & $\mathrm{BW}_{\mathrm{U}}$ & 2.763 & 0.531 & \multirow{8}{*}{ 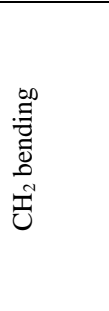 } \\
\hline & $\mathrm{M}_{\mathrm{F}}$ & 2.150 & 0.220 & \\
\hline & $\mathrm{nH}_{\mathrm{F}}$ & 1.930 & 0.440 & \\
\hline & $\mathrm{DEE}_{\mathrm{F}}$ & 2.100 & 0.320 & \\
\hline \multirow[t]{4}{*}{$1413-1416$} & $\mathrm{BW}_{\mathrm{U}}$ & 1.923 & 0.233 & \\
\hline & $\mathrm{M}_{\mathrm{F}}$ & 1.050 & 0.040 & \\
\hline & $\mathrm{nH}_{\mathrm{F}}$ & 1.190 & 0.230 & \\
\hline & $\mathrm{DEE}_{\mathrm{F}}$ & 1.590 & 0.140 & \\
\hline \multirow[t]{4}{*}{1464.02} & $\mathrm{BW}_{\mathrm{U}}$ & 5.194 & 0.287 & \multirow{4}{*}{ 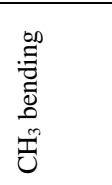 } \\
\hline & $\mathrm{M}_{\mathrm{F}}$ & 2.530 & 0.090 & \\
\hline & $\mathrm{nH}_{\mathrm{F}}$ & 3.920 & 0.060 & \\
\hline & $\mathrm{DEE}_{\mathrm{F}}$ & 3.070 & 0.010 & \\
\hline \multirow[t]{4}{*}{$1629-1638$} & $\mathrm{BW}_{\mathrm{U}}$ & 0.321 & 0.009 & \multirow{4}{*}{ 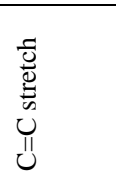 } \\
\hline & $\mathrm{M}_{\mathrm{F}}$ & 0.760 & 0.040 & \\
\hline & $\mathrm{nH}_{\mathrm{F}}$ & 0.590 & 0.020 & \\
\hline & $\mathrm{DEE}_{\mathrm{F}}$ & 0.610 & 0.020 & \\
\hline \multirow[t]{4}{*}{$1710-1713$} & $\mathrm{BW}_{\mathrm{U}}$ & 5.881 & 0.964 & \multirow{4}{*}{ 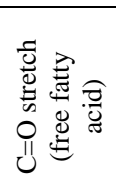 } \\
\hline & $\mathrm{M}_{\mathrm{F}}$ & 5.400 & 0.750 & \\
\hline & $\mathrm{nH}_{\mathrm{F}}$ & - & - & \\
\hline & $\mathrm{DEE}_{\mathrm{F}}$ & - & - & \\
\hline \multirow[t]{4}{*}{1735.99} & $\mathrm{BW}_{\mathrm{U}}$ & 10.654 & 4.943 & \multirow{4}{*}{ 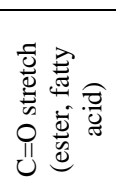 } \\
\hline & $\mathrm{M}_{\mathrm{F}}$ & 4.740 & 1.260 & \\
\hline & $\mathrm{nH}_{\mathrm{F}}$ & 9.780 & 5.180 & \\
\hline & $\mathrm{DEE}_{\mathrm{F}}$ & 8.220 & 3.490 & \\
\hline \multirow{4}{*}{$\approx 2850$} & $\mathrm{BW}_{\mathrm{U}}$ & 31.673 & 11.882 & \multirow{4}{*}{ 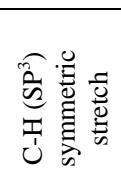 } \\
\hline & $\mathrm{M}_{\mathrm{F}}$ & 20.280 & 7.050 & \\
\hline & $\mathrm{nH}_{\mathrm{F}}$ & 30.900 & 11.820 & \\
\hline & $\mathrm{DEE}_{\mathrm{F}}$ & 22.150 & 8.520 & \\
\hline \multirow[t]{4}{*}{2918.4} & $\mathrm{BW}_{\mathrm{U}}$ & 51.726 & 23.466 & \multirow{4}{*}{ 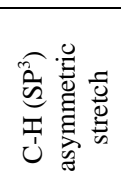 } \\
\hline & $\mathrm{M}_{\mathrm{F}}$ & 31.190 & 15.590 & \\
\hline & $\mathrm{nH}_{\mathrm{F}}$ & 50.180 & 24.480 & \\
\hline & $\mathrm{DEE}_{\mathrm{F}}$ & 35.830 & 17.240 & \\
\hline \multirow[t]{4}{*}{$3230-3390$} & $\mathrm{BW}_{\mathrm{U}}$ & 7.666 & 0.009 & \multirow{4}{*}{ 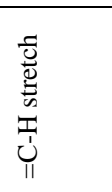 } \\
\hline & $\mathrm{M}_{\mathrm{F}}$ & 0.940 & 0.000 & \\
\hline & $\begin{array}{c}\mathrm{nH}_{\mathrm{F}} \\
\mathrm{DEE}_{\mathrm{F}}\end{array}$ & $\begin{array}{c}- \\
1.470\end{array}$ & $\begin{array}{c}- \\
0.000\end{array}$ & \\
\hline & & & & \\
\hline
\end{tabular}




\begin{tabular}{|c|c|c|c|c|}
\hline $3430-3451$ & $\begin{array}{c}\mathrm{BW}_{\mathrm{U}} \\
\mathrm{M}_{\mathrm{F}} \\
\mathrm{nH}_{\mathrm{F}} \\
\mathrm{DEE}_{\mathrm{F}}\end{array}$ & $\begin{array}{c}3.474 \\
15.520 \\
3.370 \\
15.330\end{array}$ & $\begin{array}{l}0.059 \\
0.650 \\
0.020 \\
0.210\end{array}$ & 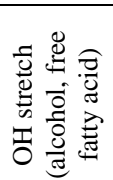 \\
\hline
\end{tabular}

$\mathrm{BW}_{\mathrm{U}}=$ unfractionated beeswax; $\mathrm{M}_{\mathrm{F}}=$ methanol fraction; $\mathrm{nH}_{\mathrm{F}}=\mathrm{n}$-hexane fraction; $\mathrm{DEE} F=$ diethyl ether fraction

\section{B. Antimicrobial activity}

The antimicrobial activities of the beeswax extracts and whole beeswax against different bacteria and fungi (moulds and yeasts) are shown in Table 4. The inhibition zones varied amongst the beeswax extracts and whole beeswax. According to the analyses among the tested bacteria, Streptococcus pneumonia $(16.5 \mathrm{~mm})$ was the most sensitive in beeswax dimethyl sulphoxide (DMSO) fraction, and the sensitivity of the bacteria decreased as follows: Staphylococcus epidermis $(15.5 \mathrm{~mm}) \quad>$ Streptococcus pyogenes $(15 \mathrm{~mm})$. Streptococcus pyogenes was the most sensitive in beeswax n-Hexanefraction $(9 \mathrm{~mm})$ and beeswax diethyl ethyl (DEE) fraction $(4 \mathrm{~mm})$ while Klebsiella pneumonia $(14.5 \mathrm{~mm})$ was the most sensitive in beeswax methanol fraction. Staphylococcus aureus $(5 \mathrm{~mm})$ was the most sensitive in unfractionated beeswax followed by Staphylococcus epidermidis and Streptococcus pyogenes with zones of inhibitions of $4.5 \mathrm{~mm}$.

According to the analyses among the tested fungi, Candida albicans was the most sensitive in all the beeswax fractions and unfractionated beeswax sample with the highest zone of inhibition of $19 \mathrm{~mm}$ in beeswax DMSO fraction, followed by Cordycepsmilitaris which was sensitive to beeswax DMSO and methanol fractions only.

The variation in the antimicrobial activities of tested beeswax fractions may be due to the different bioactive compounds/ constituents present in each of the fractions. The beeswax fractions, especially the DMSO and methanol fractions used in the study were found effective against most of the test microorganisms and showed a pronounced inhibitory effect on Candida albicans. The finding was also reported by [17]. In accordance with the present results, previous studies have demonstrated that beeswax extracts had antimicrobial activities against $S$. aureus, $C$. albicans, Streptococcus pyogenes, Pseudomonas aeruginosa, Escherichia coli, and Streptococcus epidermidis([17], [18]). According to [19], the effectiveness of beeswax extracts against pathogenic microorganisms suggests a potential future use of beeswax extracts in food processing as a preservative agent.

Table IV. Inhibitory Effects of Beeswax Fractions and Unfractionated Beeswax against Bacteria and Fungi (Inhibition Zone Diameter in mm)

\begin{tabular}{|c|c|c|c|c|c|c|c|c|c|}
\hline \multirow{3}{*}{ Microorganisms } & \multirow{2}{*}{\multicolumn{4}{|c|}{ Control }} & \multicolumn{4}{|c|}{ Fractions } & \multirow{3}{*}{$\mathbf{B} \mathbf{W}_{\mathbf{U}}$} \\
\hline & & & & & \multirow{2}{*}{ DMSO $_{\mathrm{F}}$} & \multirow{2}{*}{$\mathbf{D E E}_{\mathrm{F}}$} & \multirow{2}{*}{$\mathbf{n H}_{\mathbf{F}}$} & \multirow{2}{*}{$\mathbf{M}_{\mathbf{F}}$} & \\
\hline & $\begin{array}{c}\text { DMS } \\
\text { O }_{F}\end{array}$ & $\mathbf{D E E}_{\mathrm{F}}$ & $\mathbf{n H}_{\mathbf{F}}$ & $\mathbf{M}_{\mathrm{F}}$ & & & & & \\
\hline Streptococcus pneumonia & 10 & - & - & 8 & 16.5 & - & - & 13 & - \\
\hline Klebsiella pneumonia & 8 & - & - & 10 & 14.5 & - & - & 14.5 & - \\
\hline Staphylococcus aureus & 6 & - & - & 2 & 10 & - & - & 8 & 5 \\
\hline $\begin{array}{c}\text { Staphylococcus } \\
\text { epidermidis }\end{array}$ & 6 & - & - & 3 & 15.5 & 2 & 2 & 10.5 & 4.5 \\
\hline Escherichia coli & 7 & - & - & 5 & 12.5 & - & - & 9 & 2 \\
\hline Pseudomonas aeruginosa & 8 & 2 & - & 6 & 14 & 2 & - & 9 & \\
\hline Streptococcus pyogenes & 6 & 4 & 7 & 7 & 15 & 4 & 9 & 12.5 & 4.5 \\
\hline Beauveriabassiana & 4.5 & - & - & - & 6 & - & - & - & - \\
\hline Cordycepsmilitaris & 6 & - & - & 10 & 12.5 & - & - & 15.5 & - \\
\hline Candida albicans & 9.5 & - & - & 8 & 19 & 6 & 5 & 17 & 15 \\
\hline
\end{tabular}

$\mathrm{DMSO}_{\mathrm{F}}=$ dimethylsulphoxide fraction; $\mathrm{DEE}=$ diethyl ether fraction; $\mathrm{nH}_{\mathrm{F}}=\mathrm{n}-\mathrm{Hexane}$ fraction; $\mathrm{M}_{\mathrm{F}}=$ methanol fraction; $\mathrm{BW}_{\mathrm{U}}=$ unfractionated beeswax

\section{CONCLUSION}

The result show that the chemical parameters of the unfractionated beeswax were within the ranges of international standards but most for the fractions were outside the ranges for the unfractionated beeswax. There were variations in the properties and compositions of the fractions.
The n-hexane and diethyl ether fractions were richer in esters and hydrocarbon; while the methanol and DMSO fractions were richer in unsaturated free fatty acids and fatty alcohols. It could be inferred that the beeswax sample and its fractions contain different functional groups (various chemical 
compounds) and in different proportions which account for their structural complexity.

The research has demonstrated that beeswax fractions studied possess antimicrobial activities against bacteria and fungi and some of the fractions have stronger activities than the unfractionated wax. The inhibitory effect of the beeswax extracts was found to be solvent-dependent. Among the tested extracts, the best inhibitory effects were shown by the beeswax DMSO fraction. The overall most sensitive microorganism was Candida albicans which has the highest zone of inhibition in all the beeswax extracts and whole beeswax sample. Beauveriabassiana was the most resistant microorganism that was only inhibited by beeswax DMSO fraction.

\section{REFERENCES}

[1]. Puleo, S.L., (1991). Beeswax Minor Components: A New Approach. Cosmetics \& Toiletries, 106(2): 83-89.

[2]. Tulloch, A.P., (1980). Beeswax - Composition and Analysis.Bee World, 61:47-62.

[3]. Blum, M.S., Jones, T.H., Rinderer, T.E. and Sylvester, H.A., (1988). Oxygenated Compounds in Beeswax: Identification and Possible Significance. Comparative Biochemistry and Physiology,91B(3): 581-583.

[4]. Ferber, C.E.M. and Nursten, H. E., (1977). The Aroma of Beeswax.Journal of the Science of Food and Agriculture, 28: 511518. https://doi.org/10.1002/jsfa.2740280608

[5]. Tesfaye, B., Begna, D. and Eshetu M., (2017). Analysis of Physico-chemical Properties of Beeswax Produced in Bale Natural Forest, South-eastern Ethiopia, European Journal of Biophysics 2016; 4(5): 42-46. doi: 10.11648/j.ejb.20160405.11

[6]. US PC., (2000). United States Pharmacopoeia Convention (US PC), Inc., National Publishing. National Formulary, 19, 25362537.

[7]. FAOUNR, (1996). Value-added Products from Beekeeping, Food and Agriculture Organization of the United Nations Rome (FAOUNR) 1996, FAO AGRICULTURAL SERVICES BULLETIN No. 124, ISBN 92-5-103819-8. Retrieved on 02/02/2021 from http://www.fao.org/3/w0076e/w0076e00.htm\#con
[8]. Tulloch, A.P. and Hoffman, L.L., (1972). Canadian Beeswax: Analytical Values and Composition of Hydrocarbons, Free Acids and Long Chain Esters. Journal of the American Oil Chemists' Society, 49, 696-699.

[9]. Koga, N., (2001). Prosperities and Utilization of Beeswax.Honeybee Science, 21: 15153.

[10]. Aichholz, R. and Lorbeer, E., (2000). Investigation of Comb Wax of Honey Bees with High Temperature Gas Chromatography and High-Temperature Gas Chromatography-Chemical Ionization Mass Spectrometry.11. Journal of Chromatography A, 833: 75-88.

[11]. Dorset, D.L., (1999). Development of Lamellar Structures in Natural Waxes- An Electron Diffraction Investigation.Journal of physics D: Applied physics, 32: 1276-1280.

[12]. Beverly, M.B., Kay, P.T. and Voorhees, K.J., (1995). Principal Component Analysis of the Pyrolysis-Mass Spectra from African, Africanized, and European Beeswax.Journal of Analytical and Applied Pyrolysis, 34: 251-263.

[13]. Agbagwa, O.E. and Okolo, I., (2012). Antibacterial Activity of Honey and Propolis Marketed in Nigeria Using Well-In-Agar and Disc Diffusion Method. International Research Journal of Microbiology, 3(3): 101-105.

[14]. Adgaba, N., (2007). Physical and Chemical Properties of Ethiopian Beeswax and Detection of Adulteration.Ethiopian Journal of Animal Production, 7(1): 39-48.

[15]. Bogdanov S., (2004). Beeswax: Quality Issues Today. Bee World, 85: 46-50.

[16]. AMIC., (1968). American Beeswax Importers and Refiners Association Inc. (1968).The United States Pharmacopeia24/National Formulary-19, National Publishing, New York, USA, 2536-2537.

[17]. Ghanem, N., (2011). Study on the Antimicrobial Activity of Honey Products and Some Saudi Folkloric Substances. Research Journal of Biotechnology, 6: 38-43.

[18]. Ka'caniová, M., Vukovi'c, N., Chlebo, R., Haš cík, P., Rovná, K., Cubon, J., Dżugan, M. and Pasternakiewicz, A. (2012). The Antimicrobial Activity of Honey, Bee Pollen Loads and Beeswax from Slovakia.Archives of Biological Science Belgrade, 64(3): 927-934.

[19]. Feliciolia, A., Ciliaa, G., Mancinia, S., Turchia, B., Galavernac, G., Cirlinic, M., Cerria, D. and Fratinia, F., (2019).In Vitro Antibacterial Activity and Volatile Characterisation of Organic Apismelliferaligustica (Spinola, 1906) Beeswax Ethanol Extracts. Food Bioscience, 29 102-109 